\title{
Gente estranha: um olhar psicanalítico para o autista
}

\author{
Maria Emilia Lino da Silva \\ Pontifícia Universidade Católica de Campinas
}

\begin{abstract}
Assessorando uma pesquisa sobre Autismo, a autora busca contato direto com o tema e se interroga sobre a sua possibilidade de comunicação com essas crianças "encerradas em si mesmas". Em uma escola para autistas, ela se encontra por duas vezes com uma criança de quatro anos. Quando haveria o terceiro encontro, a menina já saíra da escola. Desses dois encontros ficou a comunicação, precária em termos de significação, mas rica em intensidade emocional. Dois fatos se destacaram: ter sido reconhecida um mês depois e o surgimento de uma frase, primitiva em sua concisão, mas que cumpria sua função.

Palavras-chave: autismo, psicanálise, linguagem, comunicação, interação autista.
\end{abstract}

\begin{abstract}
The people find strange: a psycoanalitic look to the autistic - a pilot study

Advising a research on Autism, the author looks for direct contact with the theme and it is interrogated about its communication possibility with those said children contained in themselves. In a school for autists she meets for twice with a four year-old child. When there would be the third encounter the girl had already left the school. Of these two encounters remained the communication, precarious in significant terms but rich in emotional intensity. Two facts stood out: to have been recognized later one month and the appearance of a sentence, primitive in its conciseness, but that executed its function.
\end{abstract}

Key word: autism, psychoanalysis, language, communication, autistic interaction.

Os psicóticos são portadores de distúrbios derivados de um estágio ainda mais precoce e básico. Suas dificuldades e problemas são especialmente aflitivos. Por não serem inerentes, não fazem parte da vida, e sim da luta para alcançar a vida - o tratamento bem-sucedido de um psicótico permite que o paciente comece a viver e comece a experimentar as dificuldades inerentes à vida. Provavelmente, o maior sofrimento no universo hu-

Endereço para correspondência: Departamento de PósGraduação em Psicologia - PUC-Campinas, Rua Waldemar César da Silveira, 105 - Swift, CEP 13045-270, Campinas, SP. mano é o sofrimento das pessoas normais ou maduras. Isso não é geralmente reconhecido.

\section{D.W.Winnicott}

\section{Introdução}

Assessorando metodologicamente um grupo multiprofissional de pesquisa sobre o autismo, decidi-me, então, a experimentar o que é estar junto com esse tipo de pessoa, tentar entender um pouco como são e qual a "brecha" que se pode encontrar nas cápsulas com que se recobrem, usando para isso o instrumental psicanalítico. 
Daí o título: gente estranha. Estranha no sentido empregado por Freud ${ }^{1}$ em 1919 - e Freud, para psicanalistas, é sempre atual:

Só podemos dizer que aquilo que é novo pode tornar-se facilmente assustador e estranho; algumas novidades são assustadoras, mas de modo algum todas elas. Algo tem de ser acrescentado ao que é novo e não familiar, para torná-lo estranho.(p.277)

Esse "algo", será esclarecido mais adiante, (p. 300/301), é o retorno do reprimido, do que não queremos aceitar em nós, nem como indivíduos, nem como espécie: temos vaidade também da imagem que fazemos do que seja um ser humano. Entendo essa ambivalência de sentimentos como uma dificuldade em reconhecer certas pessoas como nossos semelhantes, e para isso criamos rótulos e diagnósticos que nos identifiquem com nossos modelos e nos distingam muito nitidamente desses desviantes.

\section{O efeito estranho da epilepsiae} da loucura tem a mesma origem. $O$ leigo vê nelas a ação de forças previamente insuspeitadas em seus semelhantes, mas ao mesmo tempo está vagamente consciente destas forças em remotas regiões de seu próprio ser. A Idade Média atribuía, com absoluta coerência, todas essas doenças à influência de demônios e, nisso, a sua psicologia era quase correta. Na verdade, não ficaria surpreso em ouvir que a Psicanálise, que se preocupa em revelar essas forças ocultas, tornou-se assim estranha para muitas pessoas, por essa mesma

razão. (Freud, op. cit., p.303)

É muito doloroso estar com pessoas que parecem recusar o mundo humano e se encapsular em um mundo desconhecido, fecharem todos os acessos, toda linguagem, mesmo de sinais, e recusarem sistematicamente nossas tentativas de um contato mais profundo que não aquele de ser usado como um instrumento para seus insondáveis desígnios - o que autoriza a denominação de "autista": enclausurado em si mesmo.

É doloroso especialmente porque, de verdade, não podemos ficar indiferentes a esse destino, a essa escolha singular, e acabamos presas fáceis de suas manipulações, assustados e fragilizados ante o reconhecimento de que, "apesar de tudo", são gente. Como a gente. E isso é muito estranho... Especialmente quando enxergamos do ponto de vista da Psicanálise e portanto, do ponto de vista de determinações inconscientes, aqui chamadas de "escolha" por falta de termo melhor.

Deste modo, resolvi que, quando fosse a Rio Preto para assessorar o grupo de pesquisa, aproveitaria para ter a minha própria aprendizagem com o autismo, enquanto realidade humana, e assim poder oferecer uma contribuição melhor, mais rica, não apenas teórica. E aprender, também.

O funcionamento mental do ser humano tem sido, para mim, um terreno fascinante de pesquisa . Para melhor desempenho nesse campo, organizei, na PUC de Campinas, onde leciono na pós-graduação, o LEPP - Laboratório de Estudo e Pesquisa Psicanalíticos. Sabe-se, porém, que quanto maior a proximidade com o objeto pesquisado, maior a dificuldade do pesquisador. Daí toda a problemática em conciliar

1. Freud,S., O estranho, In : Obras Completas, Rio de Janeiro : Imago, vol. 17, p. 275-314. 
a metodologia científica de pesquisa e o método psicanalítico de investigação do inconsciente, possível apenas através de um contato particularmente íntimo, colorido pelo interjogo transferencial.

Um modo de lidar com a dificuldade em pesquisar o semelhante tem sido colocar alguma distância entre sujeito e objeto da investigação, por exemplo através do estudo da patologia, que teoricamente distanciaria apropriadamente ambos os indivíduos envolvidos na investigação.

Um desafio se apresenta em termos dos autistas, essas pessoas tão especiais, que parecem se desviar do modo corrente de constituição mental e se embrenhar num outro terreno que nos desafia a compreensão. De nosso ponto de vista, é como se essas pessoas se recusassem a seguir os padrões comuns de desenvolvimento. Se recusassem a ser humanos, como se isso fosse terrível demais, além do que pode suportar a sua sensibilidade exacerbada e sem qualquer controle, preferindo isolar-se num mundo próprio, sem comunicação, auto-suficiente.

Nem por isso elas escapam à Cultura e retornam à Natureza. Não se tornam cidadãos normais, e no entanto não retornam à harmonia animal e nem sequer se equiparam aos bebês ou às criancinhas, como parecem fazer os deficientes mentais. Vivem num mundo à parte, ilhados, embora mantenham um contato insólito conosco que tentamos atravessar a ponte que nos separa e que nos atrai, como um continente inexplorado e cheio de mistérios a respeito de nossos próprios limites. Até onde é possível ser diferente permanecendo humano? Que outro mundo é possível habitar, fora daquele a que nossa Cultura parece nos obrigar?

O autista fornece, portanto, um duplo desafio, quer em termos de nossa capacidade de conseguir entrar em contato com o seu viver solitário e excludente, quer em termos de nos re- velar alguma pista a respeito desse imenso mistério chamado mente humana. Que fio de Ariadne é esse que nos une, através dos corredores do labirinto em que parece nos escapar? Que vínculos podemos estabelecer, quais experiências é possível partilhar? Que atrativos um pode proporcionar ao outro, que aprendizagens?

Com esse desafio em mente, a minha pesquisa consistiu em buscar, neste primeiro momento, uma linguagem comum, uma forma de comunicação de modo a que se possam partilhar experiências. Um modo de troca sobre os fenômenos que acontecem no mundo interno, como a alegria e a saudade. De que modo, apesar de habitarmos mundos tão distantes, podemos encontrar um modo de trocar experiências, aceitando o idioma do outro sem abdicar do nosso, traduzindo e suportando as deformações e prejuízos de toda tradução?

De uma coisa estou certa: sou eu a interessada em penetrar em seu mundo, e não, pelo menos em princípio, o contrário. Sou eu, portanto, que preciso de cuidado, respeito, delicadeza na incursão, para não afugentar de vez e perder para sempre. Por isso eu preciso de um método, e o mais adequado me pareceu a escuta psicanalítica e sua atenção flutuante.

Mas sobretudo não estive sozinha. Contei, para trocar experiências e partilhar angústia, com toda uma equipe de pessoas mais íntimas que eu com essa realidade estranha, pessoas que já conseguiram algum tipo de contato e podem me orientar, embora também esperem que eu possa ajudá-las em suas tentativas. Interessante, isso: para chegarmos ao autista, ao isolado, é preciso que primeiro nós mesmos nos conscientizemos da natureza e da importância da solidariedade e da comunhão. Que a intersubjetividade seja importante para as coisas humanas não é nenhuma novidade, mas talvez possa ser de utilidade observar como, mesmo quando ela é ati- 
vamente rejeitada, não deixa de estar presente, de alguma forma.

E assim, durante o ano de 1995, além de coordenar uma equipe que, na Escola Municipal do Autista "Maria Lúcia de Oliveira", 2 em S. José do Rio Preto, investiga o autismo sob aspectos psicológicos, familiares, escolares e de saúde (incluindo o estudo genético da população autista da escola, que tem também alunos psicóticos), realizei este estudo para a minha própria aprendizagem (além da coordenação posterior dos dados de toda a equipe multidisciplinar).

\section{Estudo piloto}

A primeira tarefa foi verificar se eu conseguiria me comunicar com essas crianças a ponto de conseguir aprender com elas alguma coisa sobre o autismo. Aprender em termos de vivência e não de novas leituras, para além do que já conhecia sobre o aparelho psíquico e sobre psicoses infantis. Claro - esta imersão na bibliografia específica estava reservada para um segundo momento.

Tenho defendido esta metodologia de pesquisa $^{3}$ e verificado sua adequação com a visão psicanalítica do conhecer, especialmente com a visão de Bion ${ }^{4}$, para quem o "saber antes" impede ou pelo menos dificulta o estabelecimento de um conhecimento como um vínculo, como uma relação em que o sujeito do conhecimento e seu objeto - outro sujeito - interagem enquanto pessoas, daí resultando um conhecimento que está longe do "saber sobre", que se pode adquirir através de outros. Este saber mediado tem seu valor em um segundo momen- to, em que se avalia a própria experiência em confronto com a de outros, autores ou colegas, para uma elaboração teórica.

Preferi tentar estabelecer contato com as crianças pequenas, e não com adolescentes, mais acostumados com a Escola e com o convívio institucional. Especialmente, mais influenciadas por todos os recursos pedagógicos e terapêuticos que a Escola oferece. E também pelos menores serem supostamente mais plásticos, porque ainda em desenvolvimento.

De modo que me dirigi à sala em que as crianças menores estavam, procurando não me apegar a nenhum conhecimento prévio, nem de teorias nem de contatos ocasionais anteriores com os alunos mais velhos, nessa mesma Escola. "Sem memória, sem desejo, sem teoria", como diz Bion: a mente aberta e esvaziada para receber o novo.

Duas professoras estavam com as crianças. Estas continuavam a fazer o que faziam antes - o que inclui a aparência de nada - sem parecer se dar conta da entrada de uma estranha. A professora mais próxima iniciou uma conversa, e eu correspondi, sem parar de observar as crianças, e continuando a me sentir invisível para elas.

Depois de alguns instantes, fui "apropriada" por uma delas, que depois me levou a passear pela escola e com quem permaneci até o final da observação. No mês seguinte, quando lá voltei, ela acabou por me reconhecer e me levar novamente a passear. Infelizmente, ao retornar no terceiro mês, soube que ela havia saído da escola. Com isso eu perdi mais que um sujeito: perdi um contato humano, um envolvimento afetivo, breve, mas intenso.

2. A única escola estatal para autistas no país

3. Lino Silva, M.E., Investigação e Psicanálise (coord.), Campinas: Papirus, 171 p., 1993.

- Pensar em Psicanálise, in Investigação e Psicanálise, op. cit.

- Uma Aventura: A tese psicanalítica - Entrevista com Fábio Herrmann, in Investigação e Psicanálise, op. cit.

- O estudo do aparelho psíquico - Coletânea da ANPPEP : Pesquisa em Psicanálise, voll, n.16, p. 79-84

- Natureza e delimitaçào da pesquisa psicanalítica - op. cit., p. 85-91

4. Confira seus livros Aprendendo da Experiência e Atenção e Interpretação. 
Ficaram-me, desse encontro, como "fatos", a capacidade de iniciativa e de memória, a tremenda mobilização da afetividade no outro, a comunicação possível e a eventualidade de minhas próprias percepções, amparada na literatura sobre o assunto, mantendo minha liberdade de pensamento. Essa experiência, apesar de fragmentada, foi útil para definir o foco de observação, e decidi trabalhar o material assim colhido em termos de linguagem, entendida em sua acepção mais ampla, ou seja, como tudo o que envolva comunicação entre duas ou mais pessoas.

Um ponto importante foi a questão da memória, uma vez que minhas visitas só podem ser mensais. Não sei que tipo de percepção a menina teve de mim. De todo modo, ela me reconheceu, isto é, me distinguiu das outras pessoas, e isso viabiliza o meu esquema temporal, de visitas mensais.

O foco da observação foi o desenvolvimento de uma linguagem que possibilite uma 'comunicação verdadeira', entendida como uma troca de sentidos entre pessoas reconhecidas como tais, e não apenas como meros instrumentos da vontade da criança. Isso não implica, necessariamente, em uma linguagem verbal, e abrange todo funcionamento psíquico. As vicissitudes desse contato são avaliadas em termos cognitivos e emocionais, considerados como uma unidade.

A vantagem em participar deste estudo, para a criança, é a oportunidade de atenção individualizada a seu desenvolvimento mental, afora as possíveis contribuições posteriores aos outros profissionais que a atendem, respeitados os limites da ética clínica.

Dentro da teoria sobre o aprender da experiência era imprescindível que pudesse não me armar de teorias que me dissessem o que é o autista antes mesmo que tivesse tido contato com um. Foi assim que combinei com a equipe clínico-pedagógica, que entraria na sala das crianças menores sem nenhuma ação programada: iria apenas estar ali. Especialmente para as professoras, para quem é importante a programação de atividades, isso não soou como muito compreensível. E para lá me dirigi, como Bion diz que um psicanalista deve fazer : indo ao encontro do Desconhecido, que é um sinônimo para o Inconsciente.

\section{Eliete}

\section{- $1^{\text {a }}$ Observação, $18 / 8 / 95$, aproximadamen- te por 2 horas.}

Faltavam 10 minutos para as 9 quando entrei na sala de Fisioterapia. Sentei-me, fiquei olhando e falando com as professoras.

Duas crianças se aproximaram. Uma me tocou, ou melhor, tocou meu relógio, sapatos e corrente, que colocou para ouvir. [Foi esta a primeira surpresa: eles são capazes de iniciativa. Isso não estava nas minhas significações para o "encapsulado" da bibliografia.] Essa interação motora, oral e principalmente afetiva, durou alguns instantes. De alguma forma eu era "algo novo" na sala, e a menina se apropriou desse "algo", enquanto a outra se afastava. Mas ao mesmo tempo eu era "algo vivo", embora não soubesse dizer o quão próximo a "gente". Logo no início quis saber o nome dela: Eliete, disseram. Passado o tempo de "apresentação", ela me pegou pela mão e disse: "paxá". Entendi que queria passear. Perguntei se podia - já tinha feito os exercícios, podia sim, responderam.

Não era mais um simples explorar o "algo novo": ela usara a palavra para se comunicar, fora entendida e sua ordem teve efeito. Ordem, sim: ela mandava, eu executava e não havia dúvidas quanto a isso. Mas se eu era uma coisa, um prolongamento, era também de uma classe especial, aquela que se aciona com a palavra e isso não podia deixar de ser registrado. 
Ela me conduziu pela mão através dos pátios interno e externo, passando frente a bancos e desenhos no chão. Emitia sons, mas eu não os entendia. Ela estendia o braço e me mostrava a grade de proteção em cima do muro que separava a Escola da construção de um prédio, logo em frente. Imaginando que ela quisesse ver além do muro, tentei suspendê-la pela cintura, mas ela protestou veementemente e se afastou. Parou e ficou me esperando! Aí fui eu que mostrei que estava esperando que ela fosse mais clara.

Não havia como negar: de alguma forma, estávamos nos entendendo, talvez precariamente, como num país estrangeiro. Mas o essencial era comunicado e nos incentivava a prosseguir. Eu estava encantada com o fato de ela ter me retirado da sala e circulado comigo pelos seus domínios, mas longe das pessoas com as quais estava acostumada. Talvez simplesmente não notasse a diferença. Mas isso seria negar a sua escolha, a sua coragem. Também não podia super valorizar o fato: talvez ela tenha me escolhido como se escolhe qual sapato usar pela manhã. Sim, mas escolhera, usara e persistia.

"Paxá"! Pegou-me pela mão e levou-me ao parquinho. Alternou os três brinquedos existentes: gira-gira, balanço e trepa-trepa. Neste, não consegui que ela fosse até o 2o. lance. Falávamos as duas, porém sem muita eficiência aparente. Ou talvez, no caso, a eficiência requerida era apenas essa: continuarmos juntas.

Ela me parecia muito segura da situação, muito "na dela", achando óbvio que eu estivesse a sua disposição sem exigir-lhe nada em troca: talvez uma nova aquisição da escola. Em todos os brinquedos ela dizia “ i eu!" e eu entendia que ela queria que eu desse o impulso inicial. Depois assumia o comando da brincadeira e me dispensava, mantendo-me próxima.

No balanço começou algo que talvez tenha sido o mais próximo de uma troca. Admirei o modo como ela sabia se balançar direitinho, harmonizando corpo e brinquedo. Então quis participar de alguma forma. Não tendo o que fazer, resolvi usar a fala e comecei a dizer "vai" quando ela ia para trás, jogando o corpo e "volta", quando ela vinha para frente, se curvando. Parecia a única "participação" possível: ela com seus movimentos, eu com meus sons, sem que isso se constituísse numa interação. "Vai! volta...Vai! volta..." virou um acompanhamento ritmado para seus movimentos, algo como o som do balanço, sem que essa "coisificação" me incomodasse. Eu estava ali para observar, e observava. Duas linhas paralelas. Não mais.

Às vezes ela mostrava que queria parar, eu freava o balanço, ela saía correndo para o balanço ao lado. Tudo muito mecânico, sem função, sem significado. Eu aceitava e esperava: não tinha nenhuma significação a comunicar, nem para ela, nem para mim. Nada a fazer senão esperar que algum significado alguma hora se fizesse, nem que para isso precisasse esperar muitas observações. Aos poucos fui percebendo seus lábios se mordendo e depois ouvi "ai... óta! aai... óta!" Ela me ouviu e me imitava! Tínhamos uma frase sinal! Um som que era nosso, criado ali, no nosso encontro. Tentei ampliar para "frente-traz, li-ete, um-dois", mas ela só aceitava vai-volta. No meu entusiasmo, eu me excedera, e tive de voltar ao nosso porto: vai...volta. E assim, eu aprendia a paciência.

Vieram então chamá-la para almoçar. Antes tinham vindo buscá-la para a aula de música, achando que ela estivesse incomodando, mas ela se recusara. Eu afirmei que não me incomodava, ao contrário. Mas era difícil entender o eu que fazia, se não lhes tinha dito nada, a não ser que iniciava minha pesquisa, sem qualquer outra explicação. Depois, me trouxeram o seu dossiê. Mas, para a minha aprendizagem de comunicação, aqueles dados não diziam nada. De certa forma, frente ao corpo docente, eu era a encapsulada, a que não se comunicava. E eram 
as professoras que se esforçavam por manter contato comigo, em vão. Para mim, elas estavam sendo, naquele momento, instrumentos da Escola. Depois, a compreensão desse meu "autismo" me foi bastante útil.

Então, com o convite para o almoço, ela me deixou para seguir a moça, sem se despedir nem olhar para trás. Contudo, ao perceber que eu vinha atrás, esperou-me e pegou a minha mão. Acompanhei Eliete e me sentei a seu lado enquanto almoçava (a comida lhe era dada na boca). Vi que faltavam quinze minutos para as dez, quando a psicóloga estaria livre para conversarmos. Pensei em aproveitar esse tempo. Falei para Eliete: “eu vou mas volto, está bem? Tá," ela disse sem nem olhar, comendo.

Quando voltei, ela estava deitada sozinha em uma almofada, acordada, parecendo absorta com um objeto plástico não identificado. Falei com ela e ela pareceu não me reconhecer. Sentei-me na almofada ao lado e fiquei contemplando o movimento na sala, deixando-a em paz. Focalizei a atenção em outra criança. De repente ela se levantou, segurou a minha mão: "paxá!"

Era como se outra criança tivesse pegado algo seu, ela reagira, possessiva. No entanto, parecia mais que isso, parecia afeto. Estaria eu me enredando em suas manobras autistas? E quais seriam estas, que mecanismos mentais estariam implicados?

Voltamos ao parquinho. No caminho, eu quis ficar no pátiọ, houve uma pequena disputa corporal, ela me puxando e eu resistindo, até que cedi. Tinha sido a primeira oportunidade de me mostrar viva, desejante, e conferir sua reação a isso. Ela não se impressionou. Ela é a "dona do pedaço", não tem a menor dúvida a respeito, nem a menor curiosidade em saber quem sou. Ela o sabe: sou uma pessoa nova a seu serviço, que tem uma corrente de prata e um relógio de pulso interessantes. Fora isso, sou muito dócil e obediente e não tenho programas na cabeça . Não digo: é hora disso ou daquilo, faça assim ou assado. Obedeço apenas. Quando tento sair desse magnífico padrão, basta um breve protesto e pronto.

Vieram nos chamar mais uma vez e então, nos separamos, sem despedidas. Havia um bolo de aniversário para três aniversariantes, dentre os quais, Eliete. Reparei que tampara os ouvidos durante a cantoria alta, comia sozinha o bolo, sem ajuda. Estávamos na mesma sala, com outras pessoas, mas não nos comunicamos mais.

\section{- $2^{\mathrm{a}}$ Observação, 15/9/95, aproximadamen- te 40 minutos.}

Tinha sido marcada uma reunião das 8 às 10, na própria Escola, após a qual eu iria ver a Eliete. Estava particularmente curiosa para saber como ela me receberia depois de um mês, e se ainda se lembraria. A reunião se prolongava, às 10:45 acabei por encerrá-la abruptamente, porque sabia que às 11:30 Eliete iria embora.

Fui então encontrá-la na mesma sala, de fisioterapia. Nesse horário as atividades programadas estavam já encerradas, as crianças estavam livres pela sala e havia música de rádio.

Encontrei Eliete em pé junto a uma mesinha onde havia uma revista que ela folheava e na qual passava a mão, num gesto insólito para uma revista lisa, mas que estaria apropriado para um objeto tridimensional.

Falei com ela, mas ela me ignorou. Mesmo quando coloquei a mão do relógio em cima da revista, ela continuou fechada em seu mundo. Depois de instantes começou a dançar, sem abandonar o posto junto à revista. Balançava com a música.

Finalmente respondeu a meu convite, sem contudo me olhar. Senti que eu era a mãocom-relógio. Não tinha rosto, talvez nem corpo. "Paxá", ela disse pegando a mão. Saímos da 
sala em direção ao parquinho. No caminho, houve algumas tentativas fragmentadas de comunicação, fracassadas e sem registro na minha memória.

Chegando ao parquinho, foi direto ao balanço. Estava muito agitada. Saía de um balanço para outro, percorrendo todos os oito. Solicitava minha ajuda para se sentar, para o impulso inicial, para parar o balanço, para fazer a troca. Essas solicitações eram verbalizações precárias mas inteligíveis, sem um contato maior. Apenas um sinal, qualquer coisa entre a fala e um automatismo: havia palavras dirigidas a um interlocutor com uma intenção precisa. E, no entanto, não havia duas pessoas. Com um cachorrinho de estimação, algo assim acontece. O bichinho de estimação, no caso, era eu, claro.

Num balanço Eliete demorou-se mais, com seu jeito de cerrar forte os olhos por alguns instantes, embora tivesse seguido minha sugestão de dar as costas para o sol, o que indicava compreensão e assentimento. De repente, começou: "ôi, ota!"

Ela se lembra! "A nossa frase"! Eu me emocionei, para além da simples observação. Que era isso? Havia mesmo um nós? Se não, o que havia? Poderia ela me despertar essa emoção, caso não a conhecesse? Ou talvez só conheça o nós, e lhe falte o eu e o você? Mas era muito para um dia.

Continuamos por algum tempo nos balanços. Às vezes, só ela emitia sons. Uma, duas, ou três vezes, por instantes bastantes breves, tive a impressão de que ela me olhou. Apesar da rapidez com que o fazia, era como se eu começasse a existir, embora apenas em "flashs" efêmeros. Mas já era alguma coisa em direção à vida. Palavras novas eram ditas, embora soltas (uma vez eu perguntei se ela sabia que eu iria voltar, ela disse: "bia!)" Mas não havia ainda contexto para atribuir um significado a essa resposta.
Então ela pegou as minhas mãos e começamos a dançar, eu cantando e nós duas girando forte. Depois ela demonstrou que queria colo. Eu a peguei nos braços e comecei a cantar e dançar com ela. Foi divertido, embora eu estivesse pisando em ovos, presa a qualquer sinal da parte dela. Ela agora estava muito dócil, se aquietava e se aninhava cada vez mais. "Eliete gosta de carinho. E eu gosto da Eliete"! eu disse. Silêncio. Aos poucos, afinal ela tem 4 anos e já não é tão leve, fui parando de dançar e comecei a andar simplesmente, devagar, como se fizesse um nenê se acalmar e dormir. Ela estava quieta e silenciosa.

Chegou a moça convidando-a para ir tomar banho. Ela foi para o chão e pegou a mão da moça. Esta lhe disse para me convidar para ver como era gostoso o banho. Ela pegou a minha mão e fomos as três para o vestiário. No caminho, eu disse para ela: "eu vou, mas volto outra vez para ver Eliete”.

Chegando no banheiro ela se entregou à atividade de tirar a roupa depressa, ir para o chuveiro e pouco depois eu saí, sem me despedir novamente. Me reprovei por isso. Primeiro, porque fui convidada para algo, aceitei e saí furtivamente. Depois, porque pretendia, a partir da próxima vez, começar a marcar com mais ênfase o início e o fim. Para que nossos encontros ganhassem certa consistência, como uma sessão e não ficassem perdidos entre as várias atividades do dia.

Neste encontro o que se destacou foi a afetividade da Eliete. Apesar de saber isolar-se muito bem no seu mundo autista, é capaz também, quando a ocasião se apresenta, de estabelecer relações tênues mas efetivas como essa, a mantê-la na memória durante o tempo de separação, provocar no outro reações carinhosas, marcando sua presença e sua pessoa. De alguma forma ela sabia que havia verdade quando 
eu disse "eu gosto da Eliete." Mas que significado tem isso para ela?

\section{Elaboração}

Eliete não voltou mais à escola, por dificuldades dos pais. Eu também tive muitos problemas particulares e não pude providenciar uma nova criança para a pesquisa. Dediquei-me então, na medida do possível, à leitura sobre autismo. Muita coisa do que vivi com ela está analisada nesses livros. A capacidade de se isolar completamente, por mais que haja gente ao redor e busque atenção. A manipulação do outro como objeto e mesmo como um prolongamento de seu próprio corpo. A intensa manipulação de afeto no outro. $\mathrm{O}$ gosto pelo toque, a aversão ao olho no olho. O uso coisificado da linguagem e tudo o mais. Mas Eliete era muito mais que tudo isso. Ela era gente, apesar de estranha.

Penso, no entanto, que ainda é cedo para tentar relacionar experiência e teoria: preciso de mais vivência. Por isso apenas arrolo os livros consultados, na certeza de que serão melhor estudados quando voltar a ter contato efetivo com seu objeto de estudo.

\section{Referências Bibliográficas}

Alvarez, A., Companhia viva, Porto Alegre: Artes Médicas, 1994.

Avenburg, R., El aparato psíquico y la realidad, Buenos Aires: Nueva Visión, 1987.

Crowcroft, A., O psicótico, Rio de Janeiro: Zahar, 1979.

Geissmann, C. e P., A criança e sua psicose, São Paulo: Casa do Psicólogo, 1993.

Mazet, P., e Lebovici, S., Autismo e psicoses da criança, Porto Alegre: Artes Médicas, 1991.

Tustin, F., Barreiras autistas em pacientes neuróti$\cos$, Porto Alegre: Artes Médicas, s/d.
, Estados Autisticos en los niños, Buenos Aires: Paidós, 1987.

Winnicott, D.W., A natureza humana, Rio de Janeiro: Imago, 1990. 